\title{
Parabens analysis in cosmetics by ultrasonic extraction coupled with HPLC detection
}

\author{
Fenhua Xu, Dandan Zhao, Zhimin Liu ${ }^{*}$ \\ Faculty of Science, Kunming University of Science and Technology, Kunming,650500, China \\ *Corresponding author, E-mail: lab_chem@126.com
}

Keywords: parabens; daily cosmetics; ultrasonic extraction; HPLC

\begin{abstract}
Parabens extracted from five kinds of daily cosmetics by ultrasonic extraction were detected by high performance liquid chromatography. The optimal extraction solvent was dichloromethane. And the extraction time was $15 \mathrm{~min}$. The linear range was from 0.01 to $50.0 \mathrm{mg} / \mathrm{L}$. Parabens were found in 3 kinds of samples. The spiked recoveries of paraben in five kinds of samples were $96.36 \%-110.96 \%$ with the relative standard deviations of $0.3 \%-6.6 \%$. The proposed method is fast and accurate. It can be used for the detection of parabens in daily cosmetics.
\end{abstract}

\section{Introduction}

Parabens are widely used as anti-microbial agent in food, medicine, cosmetics and toiletries ${ }^{[1,2]}$. Parabens have a broad spectrum and excellent antisepsis capabilities, which are commonly used as preservatives in cosmetics. It is also an internationally recognized antiseptic ${ }^{[3]}$. The antimicrobial activity will improve with the increase of the alkyl chain length. But the solubility will decrease correspondingly ${ }^{[4]}$. In addition, more than two kinds of the parabens are often used at the same time to achieve synergies ${ }^{[5]}$. Personal care products, such as hand cream, facial cleanser and moisturizer, are widely used in people's daily lives. But parabens may be added into these products during the production. It can be absorbed through the skin into the body.

Routledge et al firstly discovered the estrogenic activity of parabens ${ }^{[6]}$. Darbre et al reported the concentrations of parabens in breast cancer tumor tissues of 20 patients ${ }^{[7]}$. Apparently the parabens were one of the reasons to cause breast cancer ${ }^{[8]}$. Moreover, it could produce inhibition effect to mitochondrial respiratory capacity and influence reproductive potential of humanity ${ }^{[9]}$. Therefore, parabens should be strictly controlled within limitation. Hygienic standard for cosmetics (2007 Edition, China) restricts the parabens preservatives limited dose. The upper limit of mass percentage of single ester was $0.4 \%$ and the upper limit of mixed esters was $0.8 \%$. In this paper, a fast and sensitive detection of parabens method was developed to detect parabens in personal daily cosmetic by ultrasonic extraction coupled with HPLC analysis.

\section{Materials and methods}

\section{Apparatus and reagents.}

Dionex Ultimate 3000 HPLC system (Dionex Corporation, USA) with a DAD detector, autosampler and $\mathrm{C} 18$ column ( $\mathrm{J} \& \mathrm{~K}$ Scientific LTD, $5 \mu \mathrm{m}, 4.6 \mathrm{~mm} \times 250.0 \mathrm{~mm}$ ); PS-20 Jie Kang ultrasonic cleaning agents (ultrasonic Equipment Co., Ltd. Dongguan Jie Kang).

Methyl paraben, ethyl paraben, propyl paraben and butyl paraben were purchased from Aladdin LTD. Methanol and acetonitrile were HPLC grade. The other reagents were analytical grade.

\section{Sample preparation.}

$0.10 \mathrm{~g}$ sample was dissolved by $10 \mathrm{~mL}$ solvent. Then it was extracted for $15 \mathrm{~min}$ by ultrasonic extraction. Then the supernatant was filtered through $0.45 \mu \mathrm{m}$ membrane. The filtrate was injected for HPLC analysis.

\section{Chromatographic conditions.}

The mobile phase was $60 \%$ acetonitrile solution. The flow rate was $1.0 \mathrm{~mL} / \mathrm{min}$. The detection wavelength was $254 \mathrm{~nm}$. The column temperature was set at $30{ }^{\circ} \mathrm{C}$. The injection volume was 20 
$\mu \mathrm{L}$.

\section{Results and discussion}

\section{Optimization of the extraction conditions.}

1) Optimization of the extraction solvent.

0.10 gnourishing \& hydrating toner sample was dissolved in $10 \mathrm{mLextraction}$ solvent. The extraction solvents were tested with carbon tetrachloride, methanol, dichloromethane, ethanol, and acetone, respectively. Each sample was extracted $15 \mathrm{~min}$ by ultrasonic bath. After extraction, $1 \mathrm{~mL}$ supernatant was filtered with membrane and then blown with nitrogen to near dryness. The residue was dissolved in $1 \mathrm{~mL}$ methanol. The solution was injected for HPLC analysis. The results were shown in Fig. 1. The best result could be obtained when the extraction solvent was dichloromethane. And methyl paraben could be determined in the sample. The concentration was $11.07 \mathrm{mg} / \mathrm{L}$. Therefore, the dichloromethane was chosen as the optimal extraction solvent.

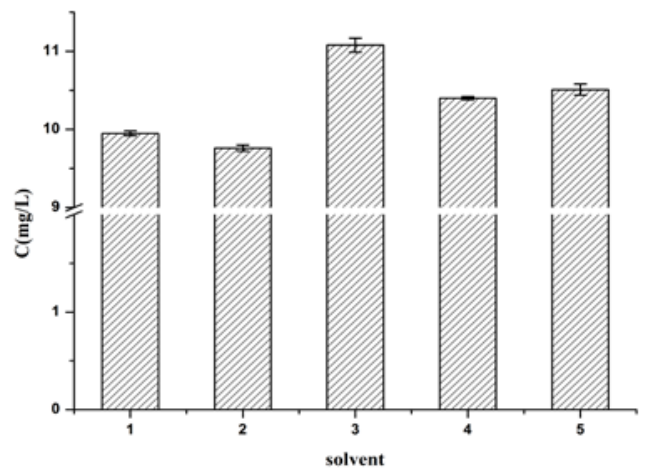

Fig. 1 Effects of different extraction solvents on extraction efficiency

1: carbon tetrachloride; 2: methanol; 3: dichloromethane; 4: Ethanol; 5: acetone

\section{2) Optimization of extraction time.}

$0.10 \mathrm{~g}$ Nourishing \& Hydrating Toner sample was dissolved in $10 \mathrm{~mL}$ dichloromethane. Ultrasonic time was set 5,10,15,20 and 25 min, respectively. The analysis results were shown as Fig. 2. With the increasing of ultrasonic time, the extraction efficiency of methyl paraben was improved and the extraction equilibrium was achieved at $15 \mathrm{~min}$. So, the extraction time was selected as 15 $\min$.

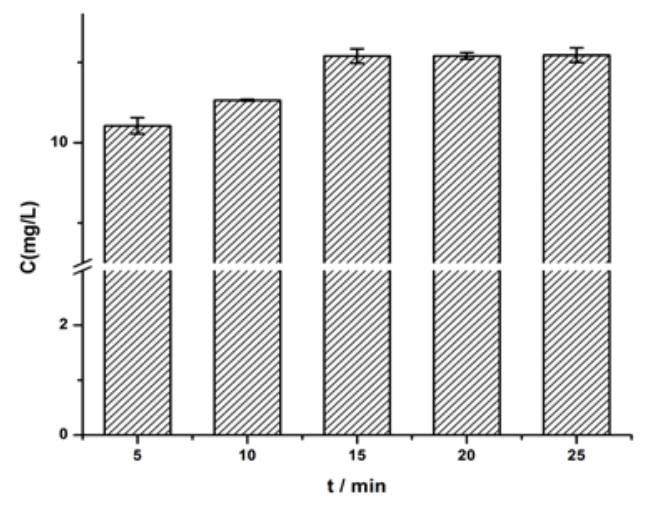

Fig. 2 Effects of extraction time on extraction efficiency

\section{Analytical method.}

The parabens standard solution was prepared in methanol solution. The concentrations were of $0.01,0.1,1.0,5.0,10.0,25.0,50.0 \mathrm{mg} / \mathrm{L}$. The linear equations for four analytes were listed in Table 1. The results showed that four kinds of parabens had a good linear relationship in the concentration of $0.01-50.0 \mathrm{mg} / \mathrm{L}$. 
Table 1 Linear equations of four paraben analytes

\begin{tabular}{lcc}
\hline Analytes & Linear equations & Correlation coefficient (r) \\
\hline methyl paraben & $\mathrm{Y}=2.09 \mathrm{X}+0.06$ & 0.9999 \\
ethyl paraben & $\mathrm{Y}=2.04 \mathrm{X}+0.13$ & 0.9999 \\
propyl paraben & $\mathrm{Y}=1.78 \mathrm{X}+0.05$ & 0.9999 \\
butyl paraben & $\mathrm{Y}=1.75 \mathrm{X}+0.02$ & 0.9999 \\
\hline
\end{tabular}

\section{Real sample analysis.}

Under the optimized conditions, five real samples of nourishing \&hydrating toner, beauty \&softening emulsion, men's facial cleanser, nourish hand cream, spearmint toothpaste, were extracted and analysized by HPLC. The results showed that methyl paraben in nourishing \& hydrating tonerwas11.07 $\mathrm{mg} / \mathrm{L}(\mathrm{RSD}=3.9 \%, \mathrm{n}=5)$, and methyl paraben and propyl paraben in the beauty \& softening emulsion were $17.84 \mathrm{mg} / \mathrm{L}(\mathrm{RSD}=1.5 \%, \mathrm{n}=5)$ and $6.82 \mathrm{mg} / \mathrm{L}(\mathrm{RSD}=5.7 \%, \mathrm{n}=5)$, respectively; and methyl paraben in men's facial cleanser was $9.34 \mathrm{mg} / \mathrm{L}(\mathrm{RSD}=3.4 \%, \mathrm{n}=5)$. The contents were lower than the legislation of "Hygienic Standard for Cosmetics" (2007 edition, China). To further verify the reliability of the method, spiked recovery experiments were carried out on five samples. The spiked level was set at the level of $1.0 \mathrm{mg} / \mathrm{L}$ for four parabens in five samples. The recovery results were shown in Table 2. The recoveries of four parabens were between $96.36 \%$ and $110.96 \%$. The relative standard deviations were between $0.3 \%$ and $6.6 \%$. The chromatogram of nourishing \& hydrating toner sample was shown as Fig. 3.

Table 2 Cosmetics of Four kinds of parabens recoveries

\begin{tabular}{|c|c|c|c|c|c|c|c|c|c|c|c|c|}
\hline \multirow{4}{*}{$\begin{array}{l}\text { Daily } \\
\text { cosmetics }\end{array}$} & \multicolumn{12}{|c|}{ Analytes } \\
\hline & \multicolumn{3}{|c|}{ Methyl paraben } & \multicolumn{3}{|c|}{ Ethyl paraben } & \multicolumn{3}{|c|}{ Propyl paraben } & \multicolumn{3}{|c|}{ Butyl paraben } \\
\hline & \multirow{2}{*}{$\begin{array}{l}\text { Found } \\
(\mathrm{mg} / \mathrm{L})\end{array}$} & \multicolumn{2}{|c|}{$\begin{array}{l}\text { Spiked } \\
(1.0 \mathrm{mg} / \mathrm{L})\end{array}$} & \multirow{2}{*}{$\begin{array}{l}\text { Found } \\
(\mathrm{mg} / \mathrm{L})\end{array}$} & \multicolumn{2}{|c|}{$\begin{array}{c}\text { Spiked } \\
(1.0 \mathrm{mg} / \mathrm{L})\end{array}$} & \multirow{2}{*}{$\begin{array}{l}\text { Found } \\
(\mathrm{mg} / \mathrm{L})\end{array}$} & \multicolumn{2}{|c|}{$\begin{array}{c}\text { Spiked } \\
(1.0 \mathrm{mg} / \mathrm{L})\end{array}$} & \multirow{2}{*}{$\begin{array}{l}\text { Found } \\
(\mathrm{mg} / \mathrm{L})\end{array}$} & \multicolumn{2}{|c|}{$\begin{array}{c}\text { Spiked } \\
(1.0 \mathrm{mg} / \mathrm{L})\end{array}$} \\
\hline & & $\begin{array}{c}\text { Recovery } \\
/ \%\end{array}$ & $\begin{array}{c}\text { RSD } \\
1 \%\end{array}$ & & $\begin{array}{c}\text { Recovery } \\
/ \%\end{array}$ & $\begin{array}{c}\text { RSD } \\
1 \%\end{array}$ & & $\begin{array}{c}\text { Recovery } \\
/ \%\end{array}$ & $\begin{array}{c}\text { RSD } \\
1 \%\end{array}$ & & $\begin{array}{c}\text { Recovery } \\
/ \%\end{array}$ & $\begin{array}{l}\text { RSD } \\
1 \%\end{array}$ \\
\hline a & 11.07 & 106.15 & 5.9 & 0 & 107.28 & 2.8 & 0 & 109.82 & 0.7 & 0 & 107.32 & 2.1 \\
\hline b & 17.84 & 108.16 & 4.9 & 0 & 103.52 & 1.1 & 6.82 & 106.05 & 6.6 & 0 & 101.44 & 3.5 \\
\hline c & 9.34 & 96.36 & 2.1 & 0 & 109.58 & 1.6 & 0 & 109.87 & 0.3 & 0 & 110.01 & 1.5 \\
\hline c & 0 & 109.25 & 0.6 & 0 & 110.43 & 1 & 0 & 109.65 & 0.7 & 0 & 109.34 & 1.9 \\
\hline e & 0 & 109.51 & 0.8 & 0 & 109.19 & 0.6 & 0 & 110.46 & 0.3 & 0 & 110.96 & 0.3 \\
\hline
\end{tabular}

a: Nourishing \& hydrating toner, b: Beauty \& softening emulsion, c: Men’s facial cleanser, d: Nourish hand cream, e: Spearmint toothpaste

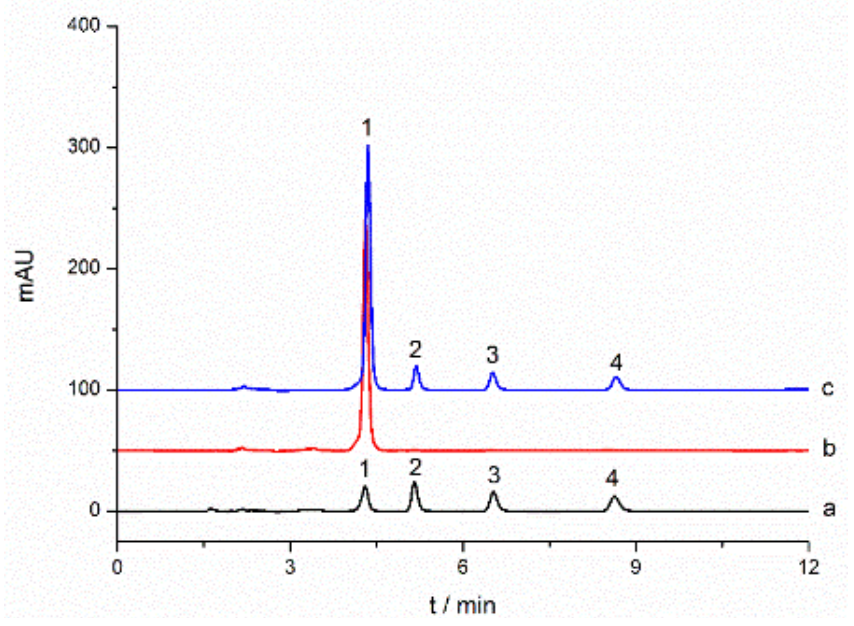

Fig. 3 HPLC analysis of nourishing \& hydrating toner sample

a. $1.0 \mathrm{mg} / \mathrm{L}$ standard solution, b. sample by HPLC analysis directly, c. spiked sample by HPLC analysis, 1: methyl paraben, 2: ethyl paraben, 3: propyl paraben, 4: butyl paraben 


\section{Conclusions}

A method of detected parabens in daily cosmetics by ultrasonic extraction coupled with high performance liquid chromatography was established. And it was used for parabens analysis in five daily cosmetic samples. Two parabens had been found in three daily cosmetic samples. The spiked recoveries of paraben in five samples were $96.36 \%-110.96 \%$, and the relative standard deviations were $0.3 \%-6.6 \%$. The method is simple and rapid. It is suitable for the analysis of parabens in daily cosmetics.

\section{References}

[1] T.B.V. Thuy, Y. Yeong-Min, C. Kyung-Chul and J. Eui-Bae: Reproductive Toxicology Vol. 29 (2010), p. 306

[2] A. Hossaini, J.J. Larsen and J.C. Larsen: Food and Chemical Toxicology Vol. 38 (2000), p. 319

[3] F. Liu, J.J. Dai, W. Liang, F. Qiu and K. Li: Occupation \& Health Vol. 23 (2007), p. 1967

[4] M.G. Soni, S.L. Taylor, N.A. Greenberg and G.A. Burdock: Food and Chemical Toxicology Vol. 40 (2002), p. 1335

[5] M.A. Farajzadeh, D. Djozan and R.F. Bakhtiyari: Talanta Vol. 81 (2010), p. 1360

[6] E.J. Routledge, J. Parker, J. Odum, J. Ashby and J.P. Sumpter: Toxicology and Applied Pharmacology Vol. 153 (1998), p. 12

[7] P.D. Darbre, A. Aljarrah, W.R. Miller, N.G. Coldham, M.J. Sauer and G.S. Pope1: Journal of Applied Toxicology Vol. 24 (2004), p. 5

[8] G. Shanmugam, B.R. Ramaswamy, V. Radhakrishnan and T. Hiroaki: Microchemical Journal Vol. 96 (2010), p. 391

[9] R.S. Tavares, F.C. Martins, P.J. Oliveira, J. Ramalho-Santos and F.P. Peixoto: Reproductive Toxicology Vol. 27 (2009), p. 1 